\title{
The orbital friction welding process for engines components in aeronautic
}

Jérémy Escaffre ${ }^{*}{ }^{1}$, Yann Lefaux ${ }^{1}$, Astrid Lenain ${ }^{1}$

${ }^{1}$ Safran Aero Boosters, Milmort, Belgium

\section{Abstract:}

Titanium alloys are key materials in engines due to their low density, their high mechanical properties and their good resistance to corrosion and oxidation. Titanium engine parts are manufactured most of the time by forging, giving good mechanical properties associated with the possibility to optimize final microstructures of the parts.

Due to design challenges consisting of making parts more robust and lighter, new processes are emerging. For some parts, friction welding can give opportunities to achieve those objectives because these assemblies are characterised by very good mechanical properties, generally higher than the raw unwelded materials [1].

As a consequence, the friction welding process is finding increasing applications as a manufacturing technology for the production of titanium alloy Ti-6Al-4V aerospace components [2]. Among those processes, the Orbital Friction Welding (OFW) technology is under study for low pressure compressors manufacturing. The BLuM® (Bladed drum, Figure 1), is constituted of a drum comprising several stages of friction-welded blades. Such architecture allows an important weight saving and performances improvement compared to current design.

The objective of the article consists of addressing the orbital friction welding process, through the description of its characteristics, the key process parameters, the microstructures and the way of ensuring good integrity of the interface.

The objective of the article consists of addressing the orbital friction welding process, through the description of its characteristics, the key process parameters, the microstructures and the way of ensuring good integrity of the interface.

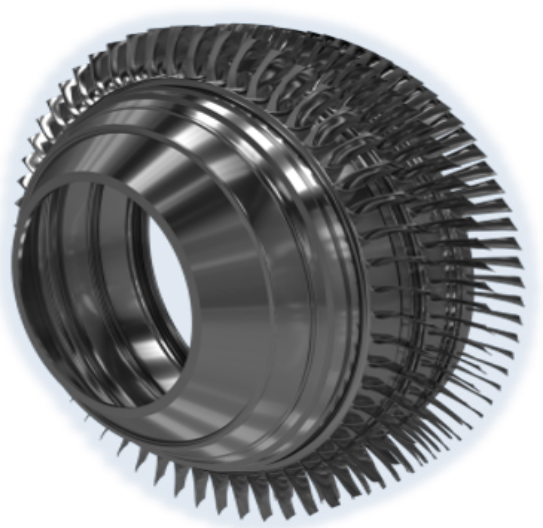

Figure 1: Design of the Bladed drum (BLuM®)

\section{Introduction:}

Considering the environment of engines and the aeronautic challenges (mass saving, sustainability and performances), titanium alloys are key material for this type of application. Especially thanks to their good corrosion and oxidation resistance which allows to avoid the use of surface treatments, and their good specific mechanical properties (Ratio of properties to the density) [3]. 
Safran Aero Boosters, which has been associated with the most major aeronautical programs in recent decades, is the world leader in low-pressure compressors for commercial turbofan engines on the medium and long-haul market. Safran Aero Boosters invests heavily in research and development in order to rise up the main challenges facing the aerospace industry and to provide more added values to customers.

The optimization of the material properties is sometimes not sufficient to improve the quality of aerospace products. That is why the development of new architectures using innovative technologies is a challenge that aerospace companies have to undertake.

Designing low pressure compressors as a one-piece part represents an important improvement. Additionally, the use of friction welding was identified as a way to take fully advantage of this new architecture. Welding by friction the blades on the drum is a sustainable process, improving considerably the "buy to fly ratio" compared to forging and machining a hog-out part of this size. Moreover, such way of manufacturing allows to avoid the use of a large size forged shape (with larger grain size) which considerably decreases the high cycle fatigue properties of the parts.

For those reasons, Safran Aero Boosters developed and validated the BLuM® (Bladed drum, Figure 1). It is constituted of a drum comprising several stages of friction-welded blades. The Orbital Friction Welding technology is used and allows, by leading to optimized architecture (cf. Figure 2), an important mass saving of $25 \%$ compared to current model, while enhancing the part life. And improves the durability by eliminating fretting issues between the spool/blade root.

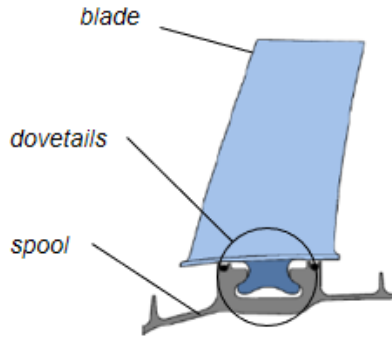

Classic architecture

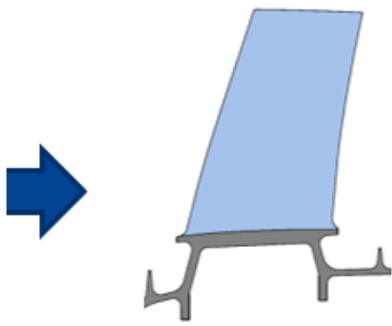

BluM architecture

Figure 2: Evolution of the architecture of low pressure compressor

\section{The orbital friction welding: principle and selection criterion}

Among all welding processes, friction welding processes are used because these assemblies are characterised by very good mechanical properties, generally higher than the raw unwelded materials [4] [5]. This is due to the fact that such welding avoids classical solidification defects and takes the benefit of dynamic recrystallization effects. Friction welding processes do not need any surface preparation before welding, additional material and atmosphere protection. This type of processes offers a good productivity with a good reproducibility thanks to their automation.

Among those processes, the Orbital Friction Welding (OFW) technology, allows to weld complex shapes like blades sections, contrary to rotational friction welding. Furthermore, this process requires less complex machine than linear friction thanks to the orbital movement which is operated by a mechanical mean, simpler and with a better ecological footprint than the hydraulic systems used to provide the linear movement. Lastly, the OFW gives a continuous movement at constant speed [6].

During all the process the drum is fixed, the blade is put on the orbital plate which gives the orbital movement, positioned on the trolley which gives the axial force and displacement (cf. Figure 3). 


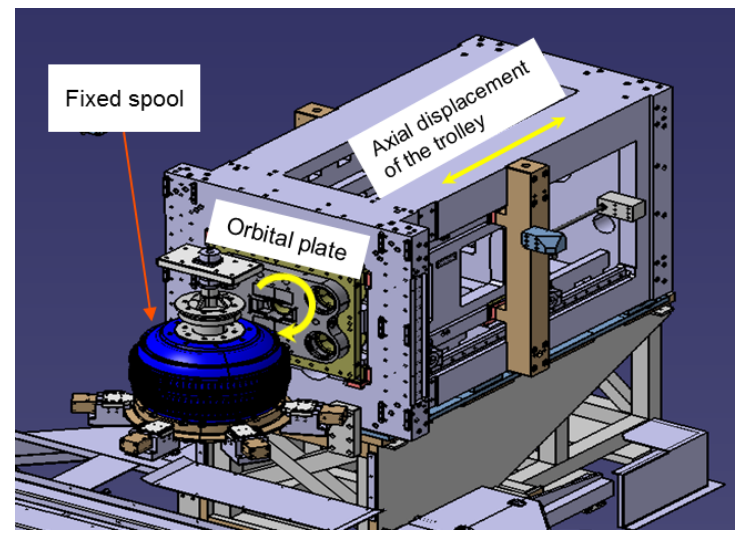

Figure 3: Schematic representation of the orbital friction machine

The OFW process is divided in three phases as shown in Figure 4. The first one, called friction 1, consists of heating the material in order to soften it with temperature staying below the fusion temperature (solid state welding process). During the second phase, called friction 2, the steady state material burn off rate is observed. When the targeted burn off is reached, a cooling under pressure is applied to solidify the welded parts. This last phase is called forge. For each phase, influent parameters directly drive final welding characteristics (dimensions, morphology, microstructures).

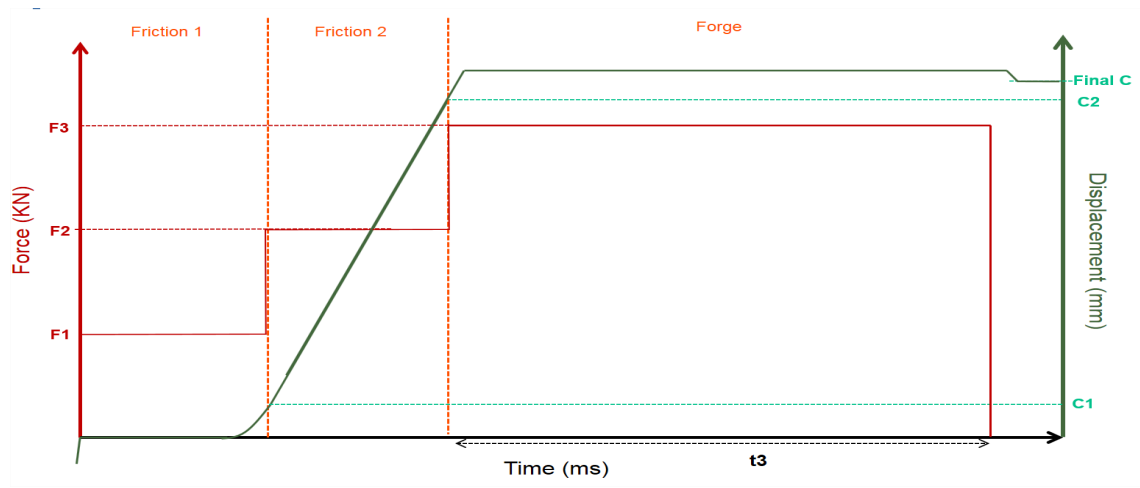

Figure 4: Schematic representation of the different process phases

Friction 1:

During the friction 1, a low force "F1" is applied for machine preservation. As friction 1 aims to heat the interface in order to soften the material, this phase is driven by displacement. Indeed, friction 1 is associated with a small displacement called " $\mathrm{C} 1$ " because it represents the burn off start, which means that the material is soften enough and starts to be expelled from the interface into the flash.

\section{Friction 2:}

During this phase, a higher force "F2" is applied. The friction 2 is a steady state between heating of the interface and ejection of the hot material in the flash giving linear burn off rate. At the end of this phase, the blade will be in final position explaining why this phase is also driven by a displacement value " $\mathrm{C} 2$ ". Thereafter, the orbital movement is stopped to start the forge phase. But during this change of phase, a forge burn off is still endured. It is important to take it into account during the determination of "C2" in order to get the final burn off goal. 
Frictions times and temperature are not driven by the machine but are undergone over this two phases.

Forge:

The objective of this phase is to cool down the welding under pressure. A high force "F3" is applied during a defined time " 3 ", long enough to cool down the interface to a temperature giving a solid state joint. During the forge, the undergone parameters are displacement and temperature.

As presented before, the driven parameters which are the frequency and eccentric of the orbital plate, the forces (F1, F2 and F3), the displacements $\mathrm{C} 1$ and $\mathrm{C} 2$ and the forging time are really important for the weld quality and characteristics. Other main parameters influence the welding. Among these: the welded section, the stiffness of the stubs and tools and the misalignments between the two surfaces to weld.

The thickness of the welding joint is driven by the welding parameters like forces, frequency, welding section and misalignments. A design of experiment was conducted to determine the influence of these parameters, in order to optimize the thickness of the welded joint.

For the BLuM®, the welded joint has also to be contained in a small area of few millimeters as specified in the design of the part. OFW makes it possible thanks to the good repeatability of the positioning of the joint and by using optimize welding parameters to have the thinner welded joint possible.

This excellent repeatability gives, furthermore, a good final blade position which is mandatory for performances of the compressor.

\section{Welding joint microstructure and properties}

As explained before, friction welding family processes are used for critical rotating engine parts thanks to the good integrity of weldings obtained. This is due to two main factors directly linked to the process characteristics: welding in a solid state and taking off the benefit of the dynamic process on microstructure. Indeed, if the microstructure of the raw material is a classical $\alpha-\beta$ forged TA6V, the orbital friction welding allows to obtain a very fine $b$ forged microstructure with excellent mechanical properties in the welded joint (cf. Figure 5).

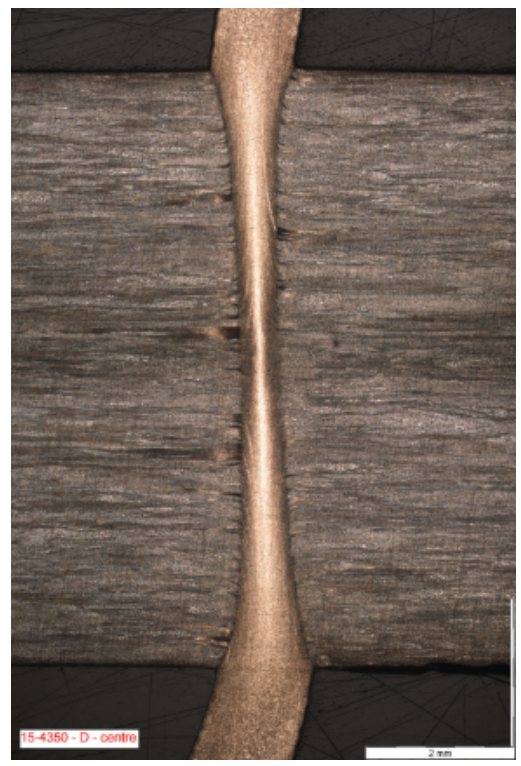

Figure 5: Observation of a typical orbital friction welded joint

As a result of the high deformation combined with a tempeature higher than $\beta$-transus and fast cooling at the interface, a fine microstructure needle-shaped is obtained in the welded joint (Figure $6 \mathrm{C}$ ). 
A thermo-mechanically affected zone is also observed between the welded joint and the raw material (Figure 6 B). This zone is affected by a temperature lower than $\beta$-transus and by smaller deformation. The result of this is a $\alpha-\beta$ microstructure with deformed and oriented grains in this zone.

The different microstructures are visible below in Figures 6 and 7.

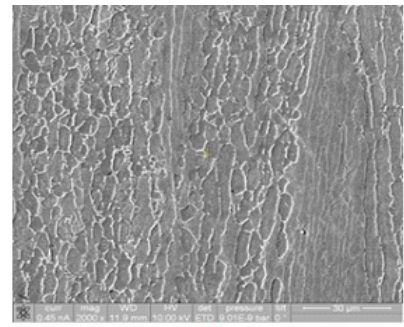

A)

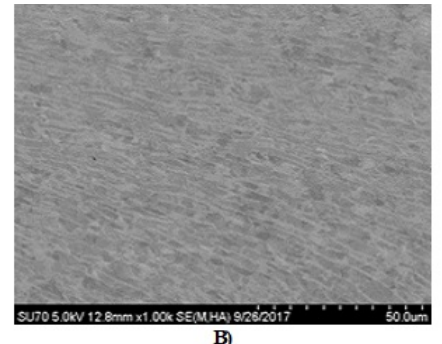

B)

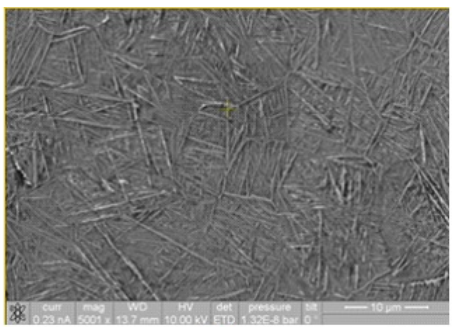

C)

Figure 6 : Typical microstructures observed on Ti64 friction welded joint.

A) Raw material; B) Thermo-mechanically affected zone; C) Welded joint

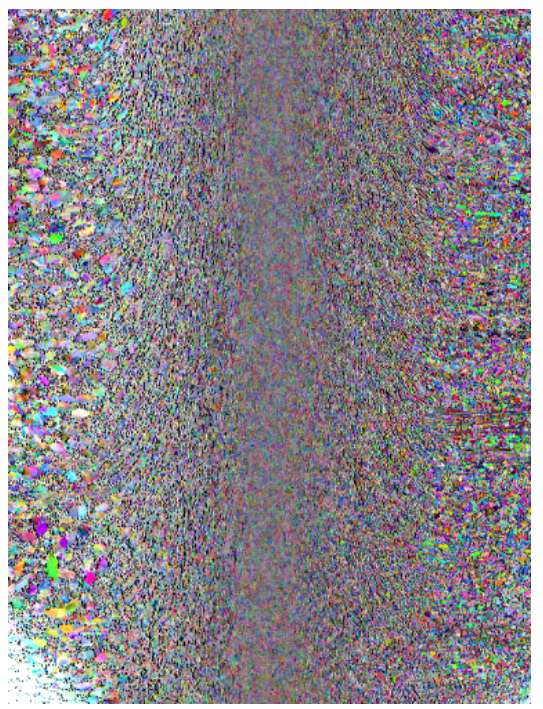

Figure 7: Forward Scatter Detector (FSD) observation of the different microstructures : Welded joint in the center, afterwards the thermo-mechanically affected zone and then the raw material.

Because of the thermo-mechanical history of the weld, residual stresses are observed in the welded area [7] [8] [9] explaining why a stress relief heat treatment is necessarily applied. The Figure 8 shows typical results of residual stress measurements on $800 \mathrm{~mm}^{2}$ welded section (parallel and perpendicular to the welded joint direction), in the middle and on the edges of the welded joint before and after stress relief heat treatment. The results show that after classical stress relief heat treatment for Ti64, the level of residual stress is more homogeneous, and decreases in the range of the measurement errors. 

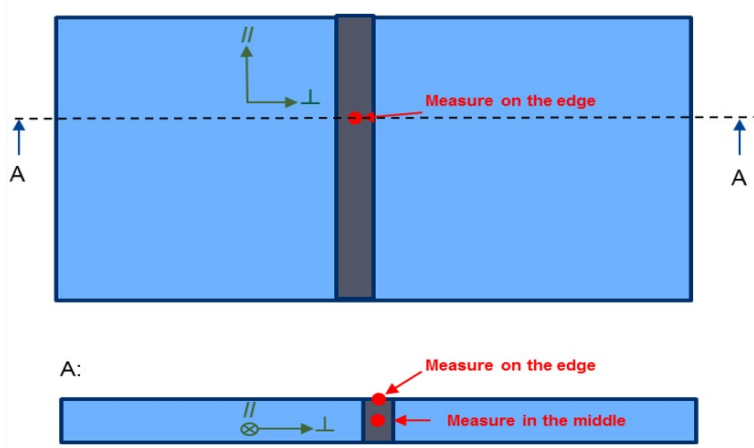

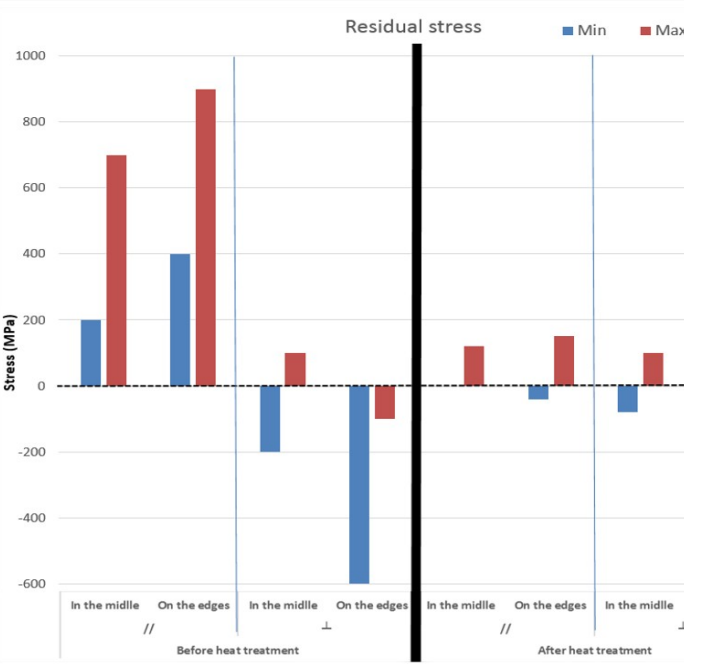

Figure 8: Residual stress measurements of the welded joint before and after stress relief heat treatment $\left(800 \mathrm{~mm}^{2}\right.$ welded section) $^{2}$

The microstructure given by the orbital friction welding possesses better mechanical properties in the welding joint. This answers to the BLuM ${ }^{\circ}$ requirement which is that the welded joint must not be a weak area of the part in fatigue and static loads. Figure 9 shows a compliant specimen, with the location of failure far from the weld.

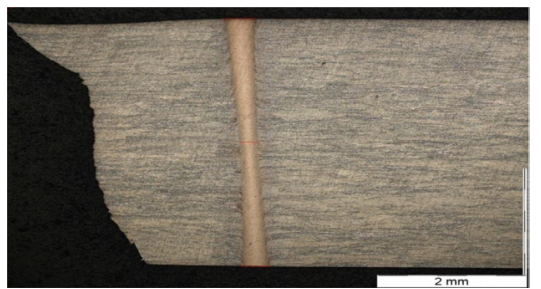

Figure 9: Location of failure of a compliant specimen (failure in the raw material)

Tensile tests were performed on welded and unwelded specimens with different material supply (blade and spool material) and are visible in Figure 10. All the failures occurred in the raw material. The ultimate and yield tensile strengths results of welded specimens are in the order of magnitude of the unwelded specimens [10]. A decrease of the elongation is observed that could be explained because of deformation is concentrated just on one half of the gage [11]. 
Ultimate tensile strenght (MPa)

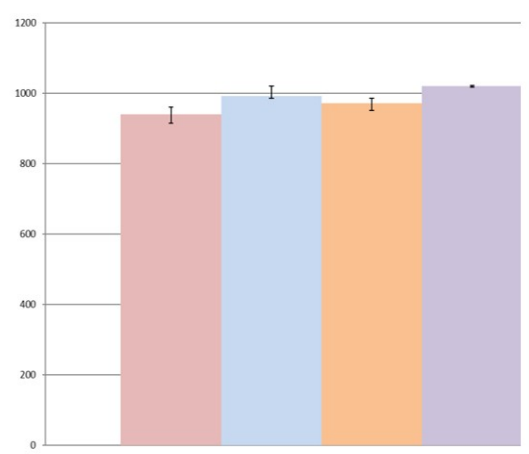

Yield tensile strenght (MPa)

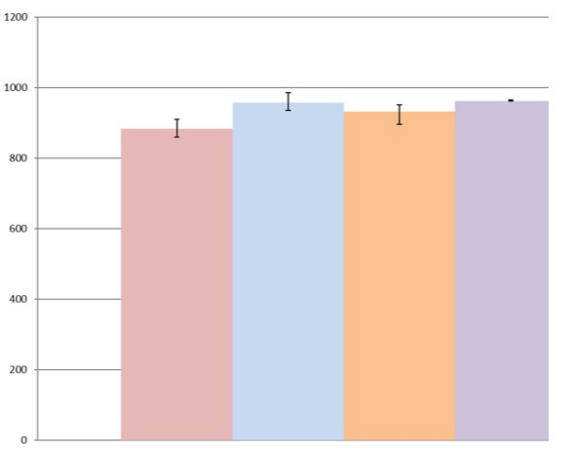

Elongation at 1

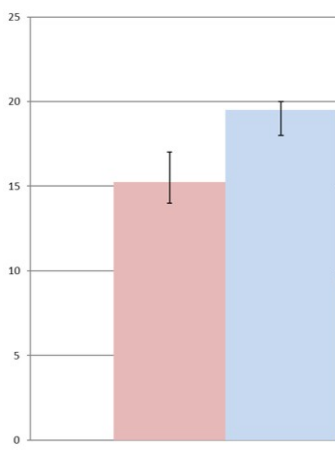

Figure 10: Tensile tests results on welded and unwelded specimens.

Fatigue tests were performed on standardized specimens in the high cycle and low cycle fatigue domain. The results show no weakness of the fatigue behaviour of the welded specimen compared to the raw material. As for tensile tests, it is worth noting that failure always occurred in the raw material, far from the welding.

Besides to test the weld properties by using standardized specimens, tests have also to be performed in order to ensure the absence of indications in the entirety of the weld (not caught by standardized specimens which represent just a small area of the weld). For this, fatigue tests were performed on technologic specimens containing $100 \%$ of the final welded joint in the gage after machining. Technologic specimens were tested in high cycle fatigue to a nominal stress in order to check that failure always occurs in the raw material. The number of cycles to failure of compliant welds (failure initiation in the raw material) tested during a typical validation of the process are visible in Figure 11. With appropriate welding parameters, the welded joint have stronger fatigue resistance than the raw material, the number of cycles to failure of welded specimens are included in the deviation of the unwelded specimens. 


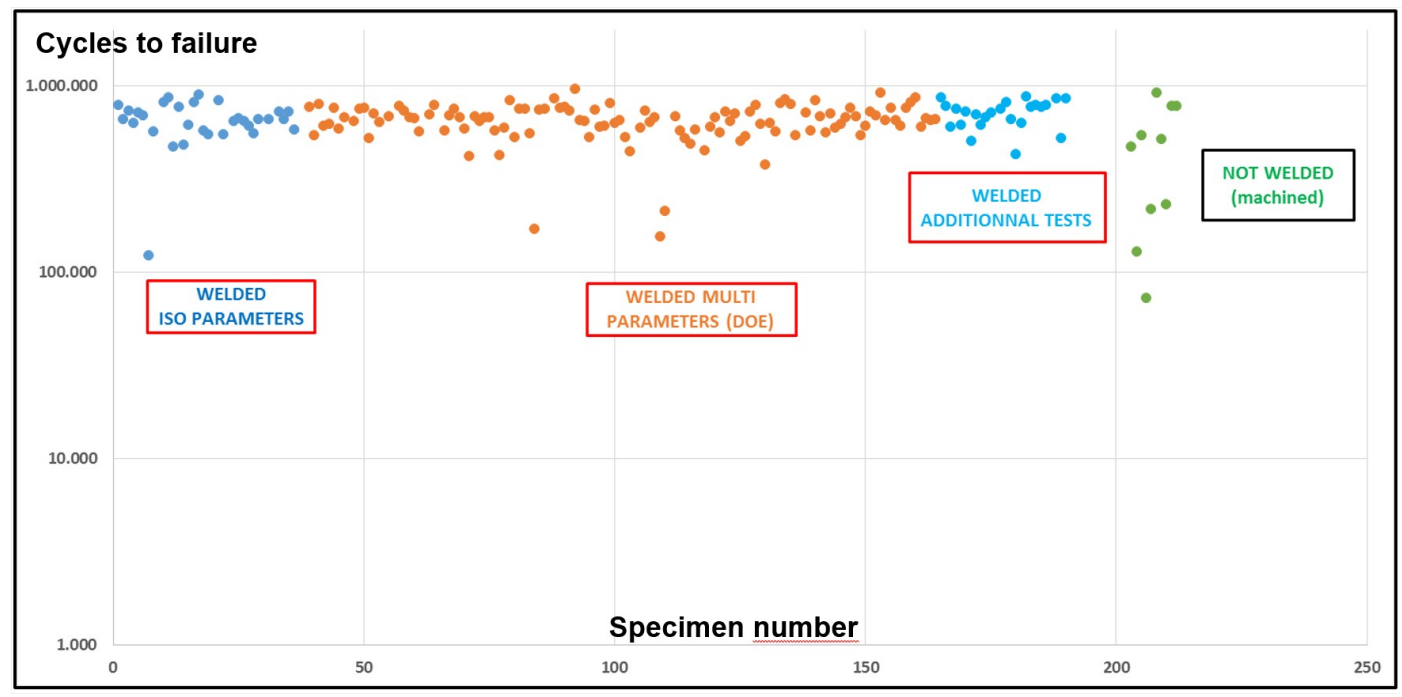

Figure 11: Fatigue results of compliant technological specimens

\section{Validation methodology}

The welded joint has to answer to several requirements, as for example the mechanical properties of the weld. Parameters have to be chosen in order to ensure the metallurgical health of the weld. The orbital friction welding is a special process, without specific atmosphere protection. Knowing the important reactivity of titanium alloys with nitrogen and oxygen, it is necessary to ensure that, with suitable parameters, contaminants created at the beginning of the welded process will be expelled into the flash (outside the final welded joint). Furthermore, welding parameters must be optimized and controlled to answer to other requirements, such as the welded joint and blades positioning, welding fixtures durability and oversize, etc...

As a consequence, in order to answer to these different requirements, all significant parameters must be understood and put under control using closed loop and statistical process control. The validation methodology is described below.

Design of experiments are conducted on rectangular welds (conservative approach compared to blade sections determined by thermal modelling), permitting to test mechanically the entirety of the welded section. The quality of the weld is evaluated as described below.

First of all, the integrity of the weld is tested with a high cycle fatigue test on technologic specimens, as explained before, after stress relief heat treatment, to be sure to test all the final volume of the weld. The fatigue test is conducted until the failure of the specimen, and the requirement of the test is that the failure must occurred outside the weld. After fatigue test, some micrographics observations are performed to know the thickness and the shape of the weld.

Several steps are used in order to validate the operating windows (schematised in Figure 12). First, several welds are welded and tested with the same parameters to evaluate the repeatability of the process. In a second time a design of experiment is used to understand the influence and the interactions of parameters on the welding characteristics (integrity and dimensions). In Figure 12 , the entirety of the tested parameters show the compliant (in green) and non-compliant space (in red). Afterwards, optimised parameters have to be found to define an operating window, tested by low, nominal and high parameters.

To complete the conservative approach, additional welding are also performed (called "worst case" campaign in Figure 12) with the worst parameters inside the operating window with cumulated defects of misalignment and stiffness, to ensure the good health of the welds throughout the whole operating window. In this case the worst parameters of the operating window (closest parameters of the non-compliant space) correspond to the low parameters. 


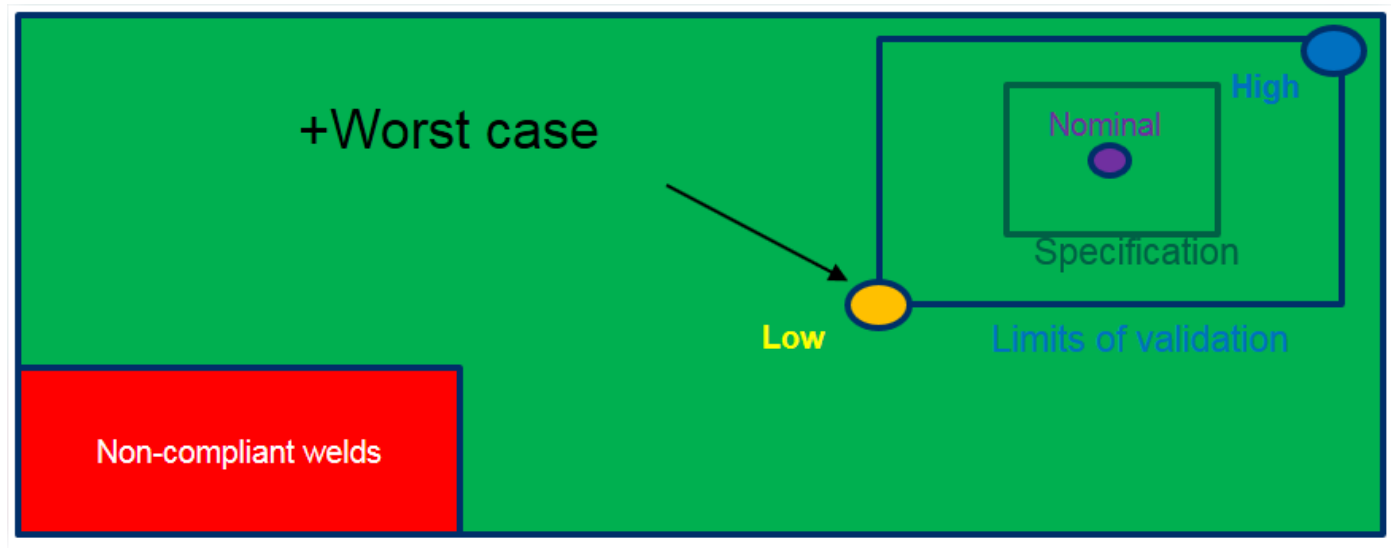

Tested parameters

Figure 12: Schematic representation of the validation methodology

\section{Conclusions}

In order to answer to the challenges of the aerospace industry, the use of alloys with high mechanical properties and low density as titanium alloys is required but not always sufficient. The design of parts has to be optimized, which sometimes, as for the BLuM ${ }^{\circledR}$, required to use innovative technologies as the orbital friction welding. The use of the Ti64 alloy and the orbital friction welding to optimize the architecture confer to the BLuM® better performances, as weight saving and life time increase compared to classic low pressure compressors. The study of the orbital friction welding on Ti64 alloy shows that the main parameters are the driven parameters (frequency, eccentric, forces, displacements and forging time), the welded section, the stiffness of the stubs and welding fixtures, and the misalignments of the mating surfaces to weld.

However, to take advantages of the orbital friction welding, and taken into account the design requirements, this process needs to be understood, and puts under control. A validation methodology using design of experiments, for the validation of the operating window and conservative tests with degraded parameters have to be performed.

The objective is to validate that staying in the operating window ensures to meet the wanted thickness and the good health of the welded joint, creating a fine forged $\mathrm{b}$ microstructure needle-shaped which provides excellent mechanical properties, better than the raw material especially in fatigue and static loading.

\section{$\underline{\text { Acknowledgements }}$}

This work has been financially supported by the Walloon region.

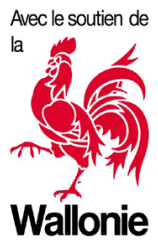

\section{References}

[1] F. Schroeder, R. M. Ward, R. P. Turner, M. M. Attallah, J.-C. Gebelin, R. C. Reed, "Linear Friction Welding of Titanium Alloys for Aeroengine Applications: Modelling and Validation" in Trends in Welding Research, Proceedings od the $9^{\text {th }}$ International Conference, June 4-8, 2012 Chicago Illinois, USA 
[2] P. Wanjara and M. Jahazi, « Linear Friction Welding of Ti-6Al-4V: Processing, Microstructure and, and Mechanical-Property Inter-Relationships » in Metallurgical Materials Transactions A, vol. 36A, p. 2149, août 2005

[3] G. Lütjering, J.C. Williams, "Introduction", "Fundamental aspects” chapters, Titanium, Springer, Pr. Brain Derby, 2003, 27-44 and 248-260.

[4] Wei-Ya Li et al., « Microstructure Characterization and Mechanical Properties of Linear Friction Welded Ti-6Al-4V Alloy » in Advanced Engineering Materials, vol. $n^{\circ} 10$, pp. 89-92, 2008

[5] J. P. Ferte, « Assemblage métallurgique dans la construction des turboréacteurs », Techniques de l’Ingénieur, BM 7778.

[6] U. Raab, S. Levin, L. Wagner, C. Heinze, "Orbital friction welding as an alternative process for blisk manufacturing" in Journal of Materials Processing Technology, 215 (2015), 189-192

[7] Anthony R. McAndrew, Paul A. Colegrove, Clement Bühr, Bertrand C.D. Flipo, Achilleas Vairis, “A literature review of Ti6Al-4V linear friction welding" in Progress in Materials Science

[8] Mark R. Daymond, Neil W. Bonner, « Measurement of strain in a titanium linear friction weld by neutron diffraction » in Physica, vol. B 325, pp. 130-137, 2003.

[9] J. Romero et al., « Effect of the forging pressure on the microstructure and residual stress development in Ti-6Al-4V linear friction welds » in Acta Materialia, vol. 5, pp. 5582-5592, septembre 2009.

[10] M. Corzo et al., " Fracture behaviour of linear friction welds in titanium alloys » in Anales de la Mecánica de Fractura, vol. 1,2007

[11] Garcia JM, Morgeneyer TF. Strength and fatigue strength of a similar Ti-6Al-2Sn-4Zr-2Mo-0.1Si linear friction welded joint. Fatigue Fract Eng Mater Struct. 2019;1-18. 